\title{
Usage of biopesticides in agriculture practices
}

\author{
Sanae BENANI ${ }^{12}$, Aziz BOUCHELTA ${ }^{1,3}$, Sanae AMINE ${ }^{1,4}$ \\ 1: Faculty of sciences, University of Moulay Ismail, Meknes, Morocco \\ 2: e-mail:sanae.benani12@gmail.com, tel: +212650043678 \\ 3: e-mail: azbouchelta@gmail.com,tel: +212664775292 \\ 4: email:amina-sanae@,hotmail.fr, tel: +212674171801
}

Key words: Ethnobotanical survey, pesticide plants, legume, brushes, Meknes.

Publication date 31/12/2020, http://m.elewa.org/Journals/about-japs/

\section{$1 \quad$ ABSTRACT}

Using pesticides is the first method to control diseases and kill pests and weeds, which are the most menacing and the biggest problem facing agriculture. It is commonly used by developing since it is the solution to increase yields and solve agriculture problems. A part from big farmers, the majority of peasant farmers are unable to pay for synthetic pesticides because of their high price. Moreover, the small fields cultivated by subsistence farmers making the use of such pesticides uneconomic. In morocco, peasant farmers use even pesticides, which are over dose or they use non-certified products. It is understood that it is very harmful for human health and environment as well. Therefore, pesticide plants do not eliminate all pests, but keep their populations under the threshold of harm, and have more advantages than synthetic pesticides. Moreover, pesticide plant extracts decompose rapidly in the environment; which limits the risk of environmental pollution and improves the sanitary quality of cultivated products; also, it controls insect pests by protecting their natural enemies rather than by spraying crops with synthetic pesticides. The aim of this study is to record all products used by farmers to control Bruchus rufimanus especially the use of bio pesticides around Meknes city (Mejjat and Sebet jahjouhe area). It was established that most of big peasant farmers use synthetic pesticides. While small farmers have only access to traditional methods such as Capsicum frutescent, Urtica dioica, salt and ash wood, if not using non-certified products among which rodenticides.

\section{INTRODUCTION}

Legumes crops play a very crucial role in Moroccan economy especially in the Region of Fez-Meknes; an area of nearly 100,000 ha for pulses in Fez-Meknes region (https:// www.agrimaroc.ma/legumineuses-fesmeknes); 66923 ha for Vicia faba major and 24767 ha for vicia faba minor (CCA Ain Taoujdate), but their production is a subject to a pressure of bio aggressors which limit their productivity and affect their storage. Most farmers use synthetic pesticides to control them; Spinor $(0.125 \%$ Spinosad) is the major pesticide used in this region (CCA Ain Taoujdate). The market's supply of plant protection products is covered by imports, which currently is higher than 12,000 $\mathrm{T}$ for an estimated annual valued of 900 million
Moroccan Dirhams and insured by more than 40 companies operating at the national level. These companies are grouped into two associations: AMIPHY including multinational companies, and ASMIPH comprehending Moroccan companies (Mojtahid, 2006). While, it is true that pesticides have made great progress in agriculture, but their use is unfortunately not without risks for both human health and the environment. We should mention the presence of residues in food, environmental pollution; with non-respect to the eco-system and making insect develop a certain resistance to the products used (M.G. van der Werf, 1997, Hayo, P Cherin et al, 2012, Health ministry, 2015). All these effects are incompatible with the essential 
objective that must be set up, to know the development of sustainable production systems and environmentally friendly for getting healthy vegetables. (FAO, 2012). Because of the low quality or illegal, due to the low level of control of sales and distribution channels, pesticides are generally not well employed, because farmers are not trained well in their handling and have little knowledge of the biology of Pests. The search for alternative sets is very important for the welfare of our environment, society and economy. When leguminous crops are grown in association with, plant-based pesticides this makes them maintain the balance between insects and necessary natural organisms (Baltazar Ndakidemi, 2016). In some cases, the use of these natural products increases yields, for a cost-benefit ratio similar to the synthetic pesticides (SO Duke, 2014). Although, the use of pesticides plants is an ancestral practice, its

\section{MATERIALS AND METHODS}

The study was carried out the site of Mejjat located between $5^{\circ}$ and Sebt Jehjouhe located between $5^{\circ} 39^{\prime} 51^{\prime \prime}$ west and $33^{\circ} 43^{\prime} 20^{\prime \prime}$ north in Meknes (figure 1). 50 farmers were interviewed (small, middle and big farmers), during this interview, semi-structured questionnaires were used to obtain information on plants used to repel insects (how do you protect your beans' knowledge is dispersed within communities (Benjamin Ndayambaje). Therefore, the identification what is got of the past is of great important. Nowadays, more and more researches are made in medicine or cosmetic rather than in agriculture. Available literature revealed that several ethnobotanical surveys have been made in morocco especially in the region of Fes Meknes for indigenous plants used in human and veterinary medicine but information concerning pesticidal plants used in this region is very limited. The aim of this study is knowing the part of use of bio pesticides in agriculture practices, collecting documentation of all known pesticidal plants among farmers, and identification of the ways they are used. It is necessary to conduct such these surveys in order to prevent ancestral knowledge from loss due to rapid urbanization and the aging of knowledgeable farmers.

stock against insects? Do you use any bio pesticides?) Including parts used, local name or vernacular name, modes of preparation and administration, they were also asked about their age, level of education, social level, the type of crops and the quantity of stored produce. The survey was conducted in the local language. 


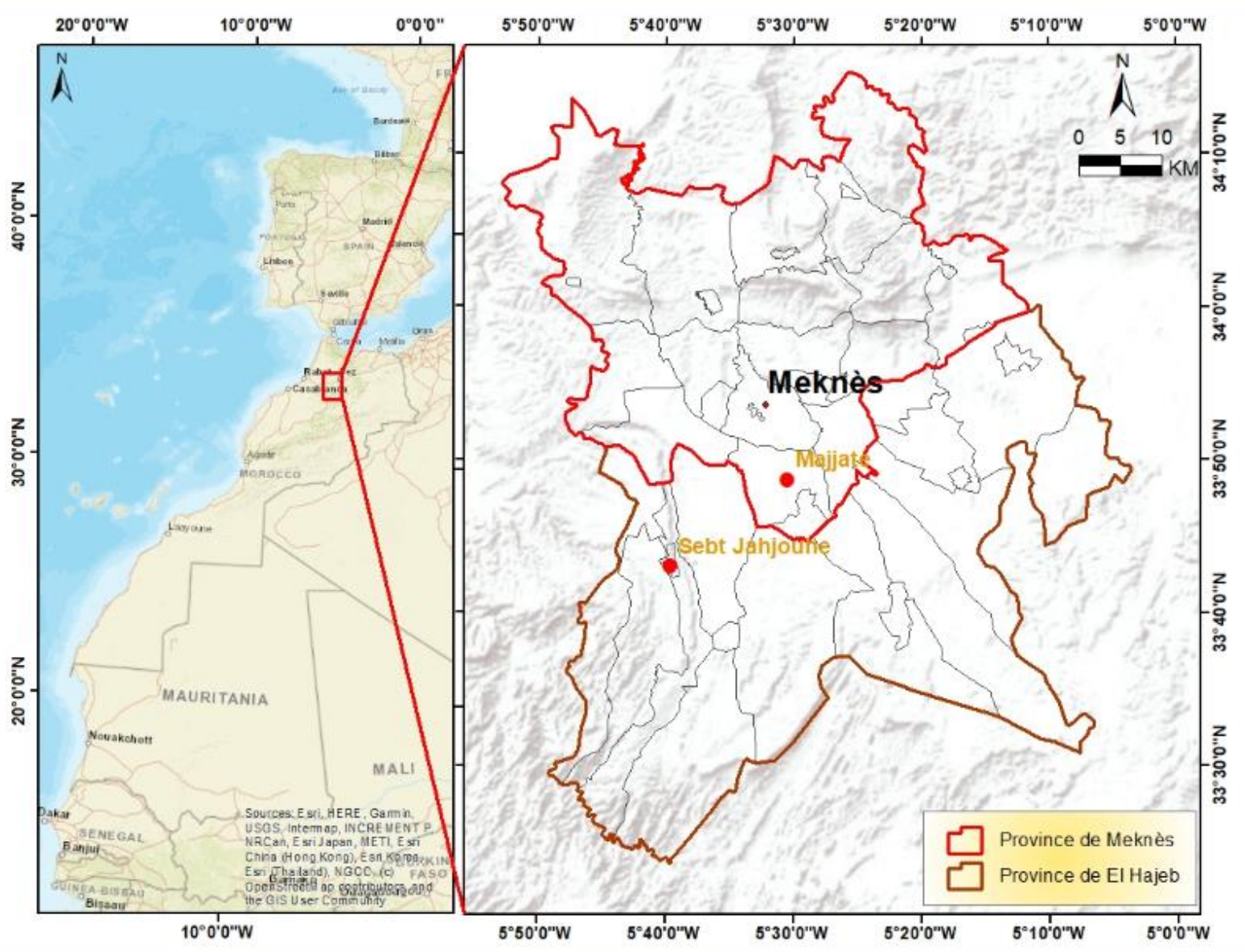

Figure1: Map of Meknes showing the study area (Mejjat and sebt jahjouhe area). Adapted from Google maps.

3

.1 Data analyses: All data was recorded in previously designed data sheets to reflect different objectives. Calculations and graphic presentations of frequencies were carried out using SPSS (V26 2019).

\section{RESULTS}

4.1 Sex, educational level and age of the farmers: A total of 50 informants from Mejjat and Sebt jahjouhe agreed to participate in this study. The result of the ethnobotanic survey revealed that the majority of the farmers are male, $(99 \%)$. The age of respondents is between 41 and 60 years for a percentage of $44 \%$ and $46 \%$ between 61 and 80 years (cf. figure 1) $38 \%$ of this farmers are illiterate and $34 \%$ of them have a primary education level $(38 \%$ and $34 \%$ respectively), only $18 \%$ of respondents have college level and 10\% have high school level (cf. figure 2).

\subsection{Type of exerted Culture and social} standing :The results showed that $58 \%$ of farmers exercises faba bean culture whereas the others have recourse to the white bean culture, chick-peas -, lenses and others legumes(, 14\%, $10 \%$ and, $8 \%$ and $10 \%$ respectively) (cf. figure 4). $62 \%$ of agriculture was small farmers, $30 \%$ was average farmers whereas only $8 \%$ was big farmers (cf. figure. 3).

4.3 Quantity of stored seeds: The interviewers showed that $30 \%$ of the farmers stock the third of their production and $70 \%$ of 
them stocks less than the third of their production (cf. figure 5).

4.4 Methods used to protect stock: 58 $\%$ of farmers interviewed use synthesis pesticides to protect their production whereas only $22 \%$ use traditional methods. (cf. figure 6). During interviews, respondents also pointed out, the difficulty of keeping save their stocks for that $20 \%$ of them confessed using rodenticides to stop the invasion of storage pests, and they reported that it is effective at $100 \%$.

4.5 Plant used in the study sites and their modes of administration: Results from
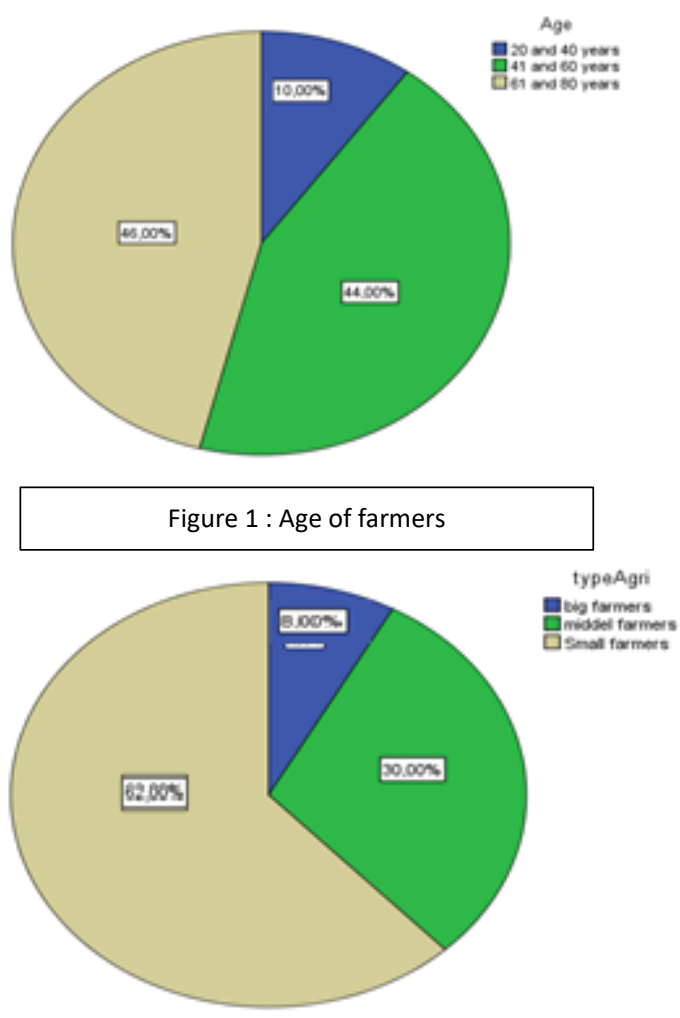

Figure 3 : social standing the present study indicated that $88 \%$ of farmers used hot pepper on combination with salt or only pepper for repelling insects (cf. figure 7) for the administration mode, farmers reported to use hot peppers, which they grind and spread . Following their experience, the efficacy of the treatment ranges between 30 and $40 \%$. The practice of adding wood ash to beans store was also reported. Ash was spread in alternate layers with beans to provide protection against storage pests.

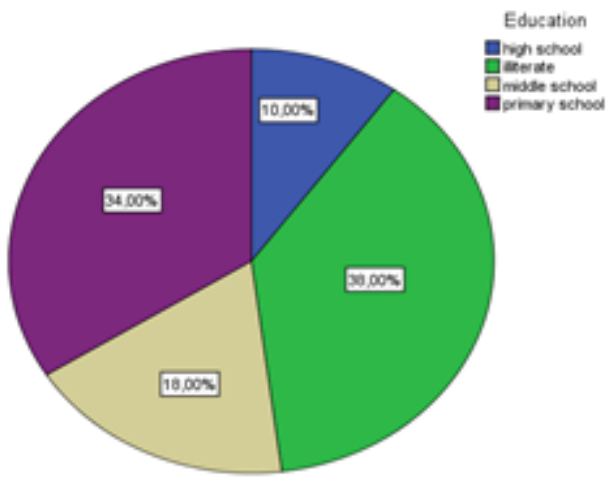

Figure 2 : Education level of farmers

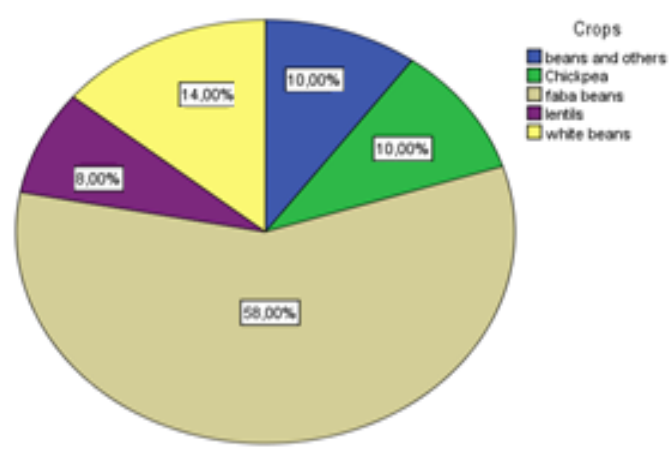

Figure 4 : Types of crops grown 

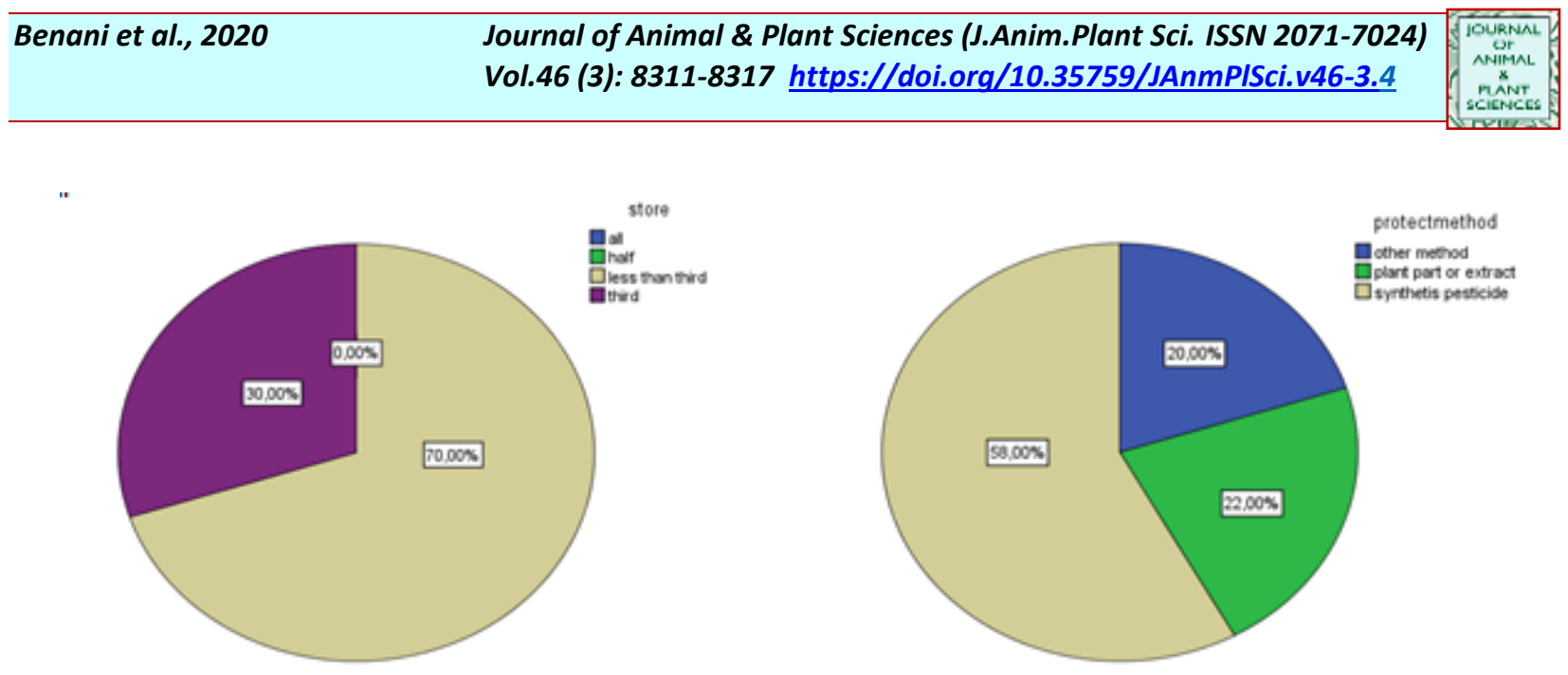

Figure 5 : Quantity of stored seeds

Figure 6: Methods used to protect stock

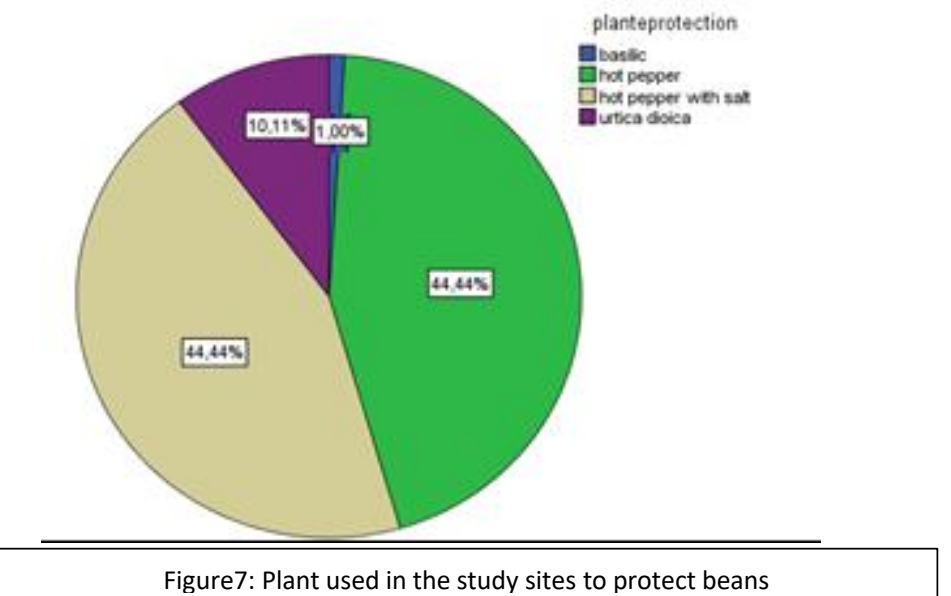

\section{DISCUSSION}

This study aims to determine the state-of-the-art related to biopesticides use by farmers. Pesticides plants are therefore a compelling alternative to synthetic pesticides. Ignacimuthu et al., (2005) showed that, the green pesticides could contribute to reduce the pest population and increase food production. They are more compatible with the environment components than synthetic pesticides. The analysis of the results study showed that the $58 \%$ of the farmers use synthetic pesticides for their effectiveness and their fast effect against the enemies of storage, exactly, big farmers search to have more production with good qualities to sell more and gain more. They consider traditional method is less effective in controlling pests when compared with the synthetic products. However, some studies showed that residues remain on the products treated by these syntheses insecticides and which are very harmful for health (Onil, 2014). The survey established by the ministry of health (Morocco) in 2015 (FAO and ONSSA, 2015), revealed that $57 \%$ who used synthetic pesticides have known intoxication will working, also the 2015 JMPR concluded that abamectin residues in a variety of crop samples were stable for at least 12 months(FAO, 2018). This ignorance of farmers about the danger of overuse these chemicals pesticide is due to their lack of training and awareness because most of them are illiterate or have a primary level (cf. figure 3). Only the old farmers and especially of small classes, still use traditional methods because they do not have enough money to buy synthetic pesticides, the majority of them use hot pepper powder or they use combination of hot pepper 
with salt. The hot pepper is known for its effect insecticides, several studies showed it, Mukondwa et al. (2014) showed the insecticides activity of the various compounds of Capsicum frutescent, also Bouchelta (2005) published that Capsicum frutescens can be used as alternative methods against Bemisia tabaci on protected tomato crop. In very few cases, urtica is also used but more by spraying plants in the fields. It has reported that Stinging nettle is used as a foliar spray on plants. Nettle also has the advantage of strengthening the natural defences of plants and having a certain repellent effect on insects (Guide de production sous régie biologique. Québec). Others peasant farmers, said that they used wood ash which has a good result of protecting stocks. Sikirou et al 2015 reported

\section{CONCLUSION}

This survey proved that most farmers are not aware of the danger of synthetic pesticides and have not idea about sustainable development, for that they use them in over dose because of their efficiency and only small farmers and especially the elderly who cannot afford these products still use their ancestral knowledge that uses environmentally friendly technology. The

\section{ACKNOWLEDGEMENTS}

I would like to thank Dr Aziz BOUCHELTA for him expert advice and encouragement, as

\section{REFERENCES}

(https://www.agrimaroc.ma/legumineuses-fesmeknes)

Aziz BOUCELTA, 2005.Bioécologie et recherché de methods alternatives de protection contre Bemisia Tabaci (Grennadius) (Homoptera: Aleyrodidae) en culture protégée de la tomate thèse.

Baltazar Ndakidemi, Kelvin Mtei, Patrick Ndakidemi, 2016. Impacts of Synthetic and Botanical Pesticides on Beneficial Insects. Agricultural sciences journal.

Benjamin Ndayambaje, Hellen Amuguni, Jeanne Coffin-Schmitt, Nancy Sibo, Martin Ntawubizi, and Elizabeth VanWormer that, using wood ash could protect the corn against stock pests. Also, after a long debate with some farmers, they confessed that they use rodenticides in the form of tablet that they put in fabrics spangled which they places in stocks, its right that this method is $100 \%$ perfect as the interview revealed but it's very dangerous for human health. Smith R, H and Shore, R, F reported that the use of rodenticides effects the environmental, particularly anticoagulant rodenticides, for example, they can affect nontarget species in a variety of ways. It is necessary to add that a great amount of farmers prefer not to stock their yields in order not to have access to any kind of pesticides, so they sell most of their products if not all.

knowledge collected has to be formalized via a knowledge base and then disseminated; the concern of it is to make it known. Plant pesticides are far from replacing synthetic pesticides in field crops, they could nonetheless be a valuable alternative in vegetable production on small areas. Since it is an important resource for ensuring food security for the population.

well as all farmers for their contribute to this ethnobotanical survey.

(2019). Pesticide Application Practices and Knowledge among Small-Scale Local Rice Growers and Communities in Rwanda: A Cross-Sectional Study. International journal of environmental research and public health.

FAO 2012. La Production et Protection Intégrées appliquée aux cultures maraîchères en Afrique soudanosahélienne)

FAO and ONSSA, 2015. Etude sur le suivi de l'effet des pesticides sur la santé humaine et l'environnement.

FAO, 2011. Save and grow.

FAO, 2018. Pesticide residues in food. 
Fatima Ezzahra BENSALEK, 2018 L'utilisation des plantes médicinales pour le traitement des troubles fonctionnels intestinaux dans le contexte marocain thèse présentée et soutenue publiquement le 16/05/2018

Filière des plantes médicinale biologiques du Québec L'ortie dioïque. (2010). Guide de production sous régie biologique. Québec pp 6.

Ignacimuthu S and Jayaraj S, 2015. Green Pesticides for Insect Pest. Management.

Lamiae Bachiri, Nadia Labazi, Amine Daoudi, Jamal Ibijbijen, Laila Nassiri, Ghizlane Echchegadda Et Faouzia Mokhtari, 2015 Étude ethnobotanique de quelques lavandes marocaines spontanées. 9(3): 1308-1318.

Maodo Malick Cisse and Nalla Mbaye, 2016/2017. Quelques travaux de recherches menés dans le cadre de la lutte biologique contre les bio-agresseurs au Sénégal (Suite).
Ministère de la santé, 2015. Etude sur le suivi de l'effet des pesticides sur la santé humaine et l'environnement. Rapport final.

Mojtahid A, 2006. Nouveau contexte phytosanitaires, adaptation du secteur. Agriculture du Maghreb.14: 63-66.

Mukondwa Nsambu, Bahananga Muhigwa, Kituta Rubabura, Mashimango Bagalwa, and Sanvura Bashwira, 2014 Evaluation in vitro activity of insect alkaloid, saponins, terpenoids or Steroids extracts capscicum frutescens (solanaceae) against antestiopsis Orbitalis ghesquierei, pests of coffee trees.

Onil Samuel, 2014 Les pesticides agricoles : impact sur la santé humaine et l'environnement Institut national de santé publique du Québec INPACQ Eau et Agriculture.

Smith, R. H., Shore, R. F. (2015) Environmental impacts of rodenticides. Book: Rodent pests and their control (chap: 16).

SO Duke, 2014. The role of natural products in crop protection. Planta Medica journal 80(10). 